\title{
Influence of Thermomechanical Sequences on the Mechanical Properties of DP 800 Steel
}

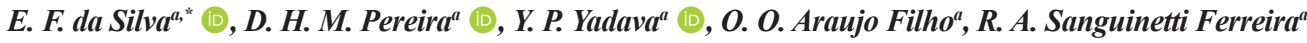 \\ ${ }^{a}$ Universidade Federal de Pernambuco, Departamento de Engenharia Mecânica, Recife, PE, Brasil
}

Received: October 08, 2020; Revised: February 22, 2021; Accepted: March 14, 2021

\begin{abstract}
The influence of thermomechanical processing sequences on the microstructure and mechanical properties of Advanced High-Strength Steels (AHSS) DP800 steel was studied. Initially, the phase transformation domains were identified by dilatometry. Based on the identification of these domains, some thermomechanical sequences were produced. In all sequences, the steel was austenitized at 900 ${ }^{\circ} \mathrm{C}$ for 20 minutes, followed by a $10 \%$ deformation (rolling) and then quenched. After tempering, the material was reheated to decompose under different conditions of time and temperature. For the decomposition, temperatures of $380^{\circ}, 480^{\circ}, 580^{\circ}$ and $680^{\circ} \mathrm{C}$ were used, in times of 15 and 30 minutes. After treatments, samples were prepared by metallography for microstructural characterization by scanning electron microscopy (SEM). The phases present in the microstructures produced by the different treatment sequences could be identified. The mechanical properties were determined by uniaxial tensile test on a servo-hydraulic machine. Some of the tested thermomechanical sequences showed better values than those required by the standard. The sequence that showed the best results was performed at $680{ }^{\circ} \mathrm{C}$ in 15 minutes. In which, an increase of $8 \%$ in the yield strength, $12.25 \%$ in the ultimate tensile strength and $97.3 \%$ in the elongation was observed.
\end{abstract}

Keywords: Thermomechanical Sequences, Mechanical Properties, AHSS DP800 Steel.

\section{Introduction}

The automobile industry has driven major developments in the entire Metal-Mechanical sector over the past few years, including the steel industry. The oil crisis of the 1970s and 1980s produced profound changes in automobiles, in order to reduce drastically their weight and fuel consumption. In addition, the engine manufacturers and the other industrial sectors, suppliers to the automotive sector (systemists), were also encouraged to develop new products that contribute to the energy efficiency of automobiles. The steel industry was responsible for the development of new steels, capable of making formability compatible with high strength, also contemplating safety and durability ${ }^{1}$.

Conventional steels such as High-Strength Low-Alloy (HSLA) and IF, of excellent formability, no longer meet the resistance needs required by this industrial segment. New steels with strength limits ranging from 600 to 1200 MPa have been produced by demand from the automobile industries, as they have excellent combinations of strength and formability ${ }^{2}$. To meet this new demand, Advanced High Strength Steels (AHSS) appeared.

AHSS of different categories have been developed in three generations in recent years. In the first generation (widespread), dual phase steels (Dual Phase - DP), steels with transformation induced by plasticity (Transformation Induced Plasticity - TRIP) and complex phases (ComplexPhase - CP) were developed. Due to the good performance they present today, almost $60 \%$ of these materials have

*e-mail: everton_fernandes_silva@hotmail.com been used in light vehicles in the automobile industry ${ }^{1}$, this reflects the ability of these first generation AHSS steels to meet performance demands

The second generation AHSS are Twinning Induced Plasticity (TWIP), lightweight Induced-Plasticity (L-IP) and austenitic stainless steels, that have elongation of $55-70 \%$ and very high strength, between 1200 and $1500 \mathrm{MPa}$. However, their cost effectiveness for automotive applications is very poor ${ }^{3}$.

The third generation of AHSS steels is still under development. Preliminary results already show that the resistance levels will easily exceed $1200 \mathrm{Mpa}$ with elongation greater than or equal to forty percent.

\section{Material and Experimental Methods}

\subsection{Material}

The material used in this study was the commercial steel AHSS type DP800 (Dual Phase), supplied in the form of sheets in thicknesses ranging from $1.85 \mathrm{~mm}$ to 1.9 $\mathrm{mm}$, supplied by a local automotive industry. The material chemical composition in the "as received" condition is shown in Table 1

\subsection{Dual Phase DP800 Steel Dilatometry Test}

Dilatometry is an effective and simple technique for studying phase transformations. The technique is based on the dilations produced during heat treatments that produce anomalies (accidents) on the curves, indicating the domains 
Table 1. Chemical composition of dual phase-DP800 steel.

\begin{tabular}{ccccccccc}
\hline & $\mathrm{C} \%$ & $\mathrm{Si} \%$ & $\mathrm{Mn} \%$ & $\mathrm{P} \%$ & $\mathrm{~S} \%$ & $\mathrm{Al} \%$ & 0,002 & 0,040 \\
\hline $\mathrm{DP}-800$ & 0,13 & 0,20 & 1,50 & 0,010 & 0,015 & 0,002 \\
\hline
\end{tabular}

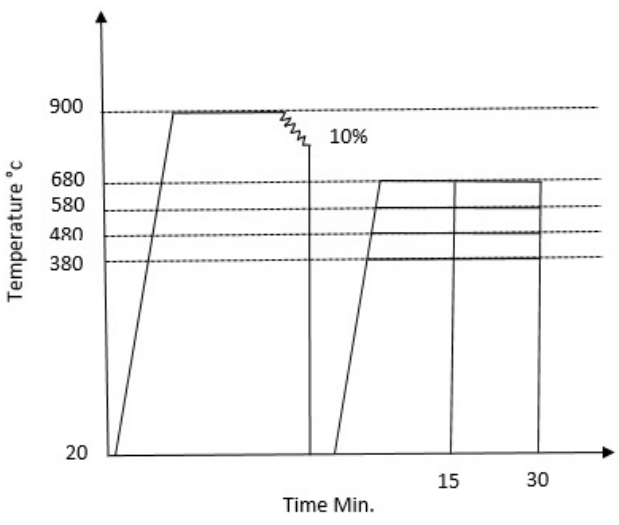

Figure 1. Thermal and Thermomechanical Sequences.

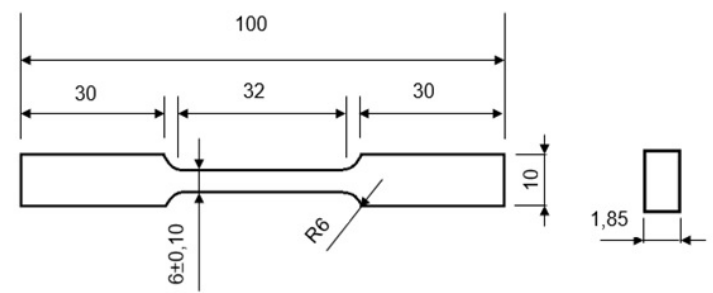

Figure 2. Specimen designed for tensile tests according to ASTM E8/E8M $-09^{4}$

of the microstructural changes produced by the phase transformations.

In this work, these tests were performed using a differential dilatometer $\left(\mathrm{T}_{\max }=1200^{\circ} \mathrm{C}\right)$ from the Laboratory of Thermometry and Thermomechanical Simulations, of the Department of Mechanical Engineering at UFPE. These tests allowed the determination of the DP800 steel phase transformation domains as a function of temperature. Based on the results of dilatometry, the thermomechanical sequences of this study were proposed, as shown in Figure 1.

The dilatometer used in the study has the following technical specifications:

- $\quad$ Temperature range: room temperature at $1200^{\circ} \mathrm{C}$;

- Heat rates: $0.01{ }^{\circ} \mathrm{C} / \mathrm{min}$ to $50{ }^{\circ} \mathrm{C} / \mathrm{min}$;

- $\quad$ Measuring range: $500 / 5000 \mu \mathrm{m}$;

- $\quad$ Sample length: $50 \mathrm{~mm}$ (max.);

- $\quad$ Sample diameter: $12 \mathrm{~mm}$ (max.);

- $\Delta 1$ resolution: $8 \mathrm{~nm}$.

\subsection{Thermal and thermomechanical sequences}

After dilatometric tests, identifying the domains of phase transformation, treatments were performed. To perform the thermal and thermomechanical sequences, two electric furnaces were used simultaneously, both monitored by type $\mathrm{K}$ (Chromel-Alumel) thermocouples. Three specimens were made for each of the 8 planned thermomechanical conditions. In total, 24 specimens were produced, in a standardized form for tensile tests. Figure 2 outlines the tensile specimens that was used in the study.

For thermomechanical treatments, $10 \%$ deformations, made in the austenitic domain, were performed in a goldsmith type rolling at a deformation rate of $1.8 / \mathrm{sec}$. The isothermal decomposition was carried out in a lead bath in four temperature ranges of $380,480,580$ and $680^{\circ} \mathrm{C}$, followed by air cooling (Figure 1).

\subsection{Mechanical tests}

In order to evaluate the mechanical properties under different treatment conditions, uniaxial tensile tests were performed according to the ASTM E8M ${ }^{4}$ standards. For these tests, a 10 ton universal servo-hydraulic machine was used. The strain data were obtained by an extensometer mounted directly on the specimens in the region most susceptible to strain. For each treatment condition, three mechanical tests were performed at a strain rate of $0.001 \mathrm{~s}^{-1}$.

\subsection{Microstructural characterization}

For microstructural characterization, metallographic steps were performed in the samples: cutting, inlaying, sanding $(220,400,600,800$, and 1200 mesh) and polishing on a carpet with $1 \mu \mathrm{m}$ diamond paste. After polishing, the chemical etching was carried out with $3 \%$ nital with an immersion time of 10 seconds, approximately.

\section{Results and Discussion}

To identify the phases present in this study, comparisons were made with the morphologies found by other authors working with the same or similar steel. Bhadeshia and Honeycombe ${ }^{5}$, presents a standardization for the morphologies of the different micrographs, also adopted in this study.

Silva ${ }^{6}$, working with steel DP 800, studied the thermal and thermomechanical sequences similar to ours (temperature and treatment time) and performed XRD both on the material as received and on the treated samples to identify the phases. In their diffractograms, the phases, bainite, ferrite and retained austenite, obtained by isothermal decomposition of austenite at $600^{\circ} \mathrm{C}$, were identified.

The microstructure of the as received material used in this work presented different phases, contrary to what is reported by different authors ${ }^{6-8}$ According to these authors, AHSS steels of this category traditionally have martensite islands in a ferritic matrix.

The microstructure of Figure 3 shows that the as received material has a mixture of martensite (blue circle), pearlite (white circle), MA constituent (red circle), retained austenite (green circle), upper bainite (yellow circle) and the ferritic phase (orange circle).

The microstructure, Figure 4, produced by the $380-15$ sequence which presents martensite in the blue circle, M-A constituent in the red circle and ferrite in the orange circle. 


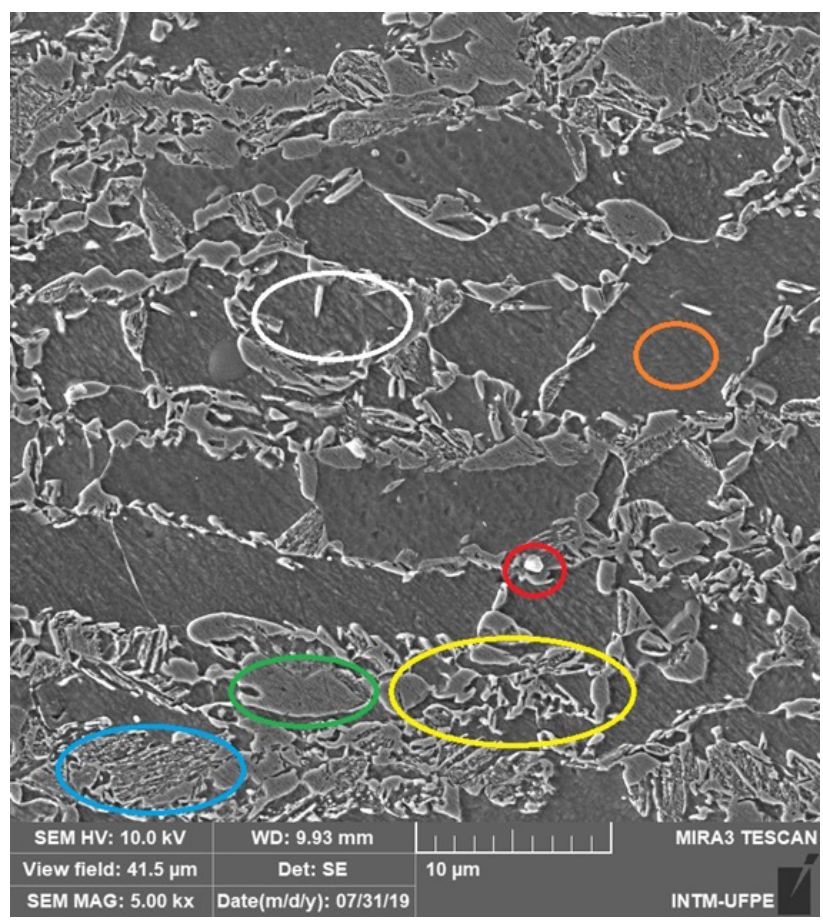

Figure 3. Microstructure of the as received material.

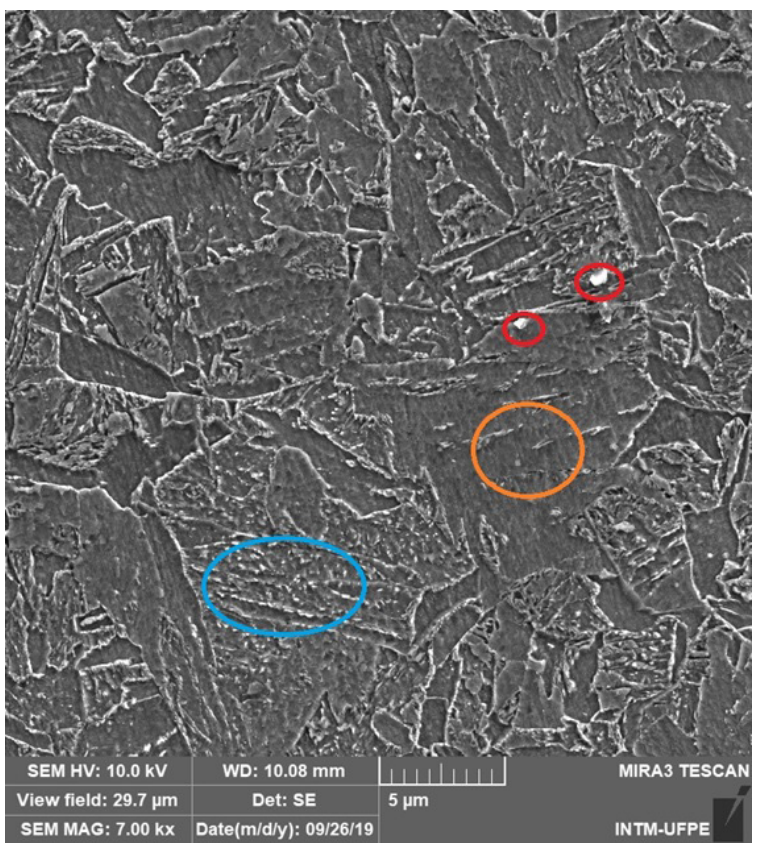

Figure 4. Microstructure of the material produced by the $380-15$ sequence.

Increasing the time to 30 minutes at this temperature of $380^{\circ} \mathrm{C}$, slight modifications were observed in the microstructure. It can be seen some lamellae of the bainite (yellow circle), besides martensite in the blue circle, ferrite in the orange circle and constituent M-A in the red circle, as shown in Figure 5.

Raising the temperature to $480^{\circ} \mathrm{C}$ and the time to 15 minutes, the sequence showed a significant change in morphology. The content of the martensite phase (in the blue circle) was reduced, while the ferritic phase (orange circle) grew, as did the bainitic phase (yellow circle), to a lesser extent. Some particles of the constituent MA (red circle) have also been found, as seen in Figure 6 .

The 580-15 sequence presented bainitic phase (yellow circle) in a smaller volume fraction and ferritic phase (orange circle) microstructure, as shown in Figure 7.

The 680-15 sequence, on temperature domain of perlite zone, showed the austenitic phase decomposing into pearlite (white circle), in addition to the ferritic phase 
Table 2. Values of mechanical properties before and after treatments.

\begin{tabular}{cccc}
\hline Sample conditions & Ultimate tensile strength (MPa) & Elongation (\%) & Yield strength (MPa) \\
\hline DP800 & $800-950$ & 10 & $500-650$ \\
\hline $\mathbf{1 ~ ( 3 8 0 - 1 5 )}$ & 915 & 9.43 & 780 \\
\hline $\mathbf{2 ( 4 8 0 - 1 5 )}$ & 817 & 11.17 & 680 \\
\hline $\mathbf{3 ( 5 8 0 - 1 5 )}$ & 731 & 13.73 & 600 \\
\hline $\mathbf{4 ( 6 8 0 - 1 5 )}$ & 702 & 19.73 & 540 \\
\hline $\mathbf{5 ( 3 8 0 - 3 0 )}$ & 965 & 11.14 & 780 \\
\hline
\end{tabular}

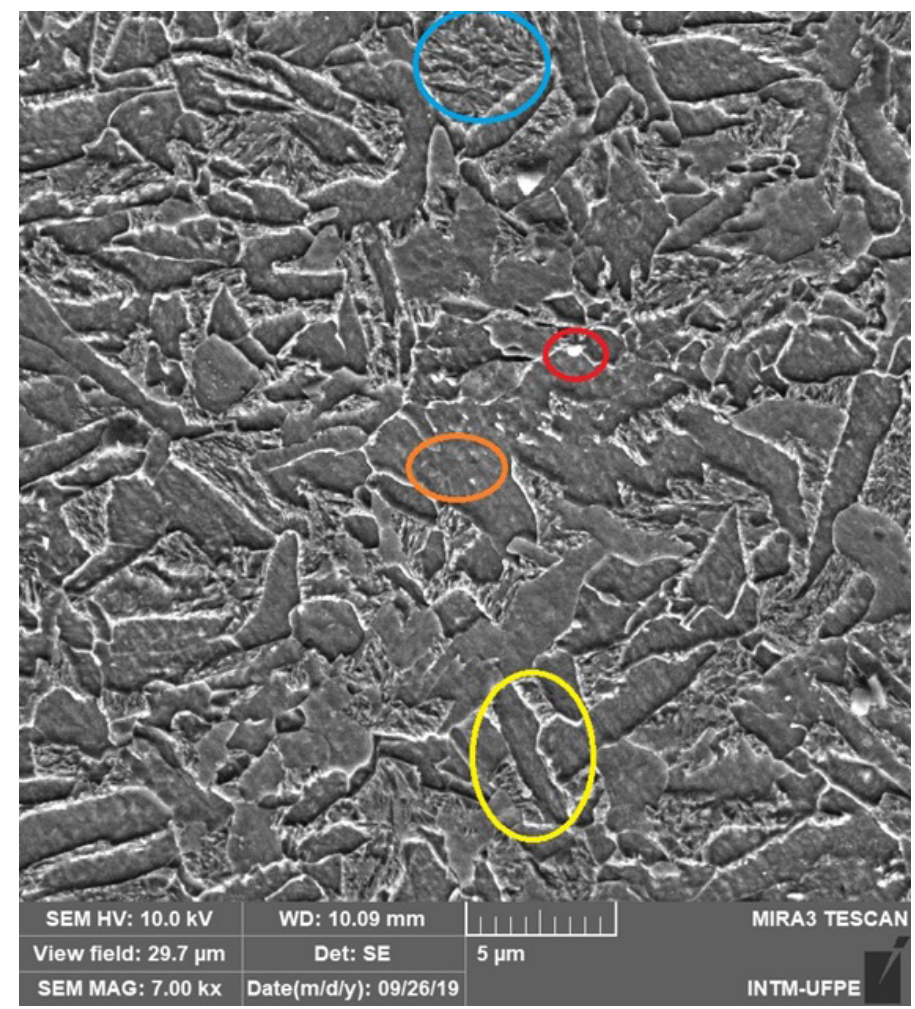

Figure 5. Microstructure of the material produced by the 380-30 sequence.

(orange circle) microstructure. Traces of the constituent M-A not yet dissolved (red circle) were also observed as seen in Figure 8.

In this work, the mechanical properties analysis was made in relation to the minimum values, according to UltraLight Steel Automotive Body - Advanced Vehicle Concept ${ }^{9}$.

After thermomechanical treatments, tensile tests were performed on the samples, in order to determine the mechanical properties. Table 2 shows the values obtained after the tensile tests.

The 380-15 sequence presented an increase either in the ultimate tensile strength $(14.35 \%)$ or in the yield strength $(56 \%)$ but a reduction in elongation $(5.7 \%)$, compared to the standardized values ${ }^{9}$. A greater amount of the martensitic phase produced by this sequence contributed to the observed reduction in the elongation.

Similarly, the 380-30 sequence presented a yield strength $56 \%$ greater than the minimum value informed by the standard, an ultimate tensile strength $20.62 \%$ greater than the minimum value and an increase in the elongation (11.4\%). This result is justified by the presence of martensite in a volumetric fraction greater than the as-received material.
In addition to the greater volume, the greater dispersion of the martensite ensures greater resistance, which is added to the appearance of bainite.

The 480-15 sequence presented a yield strength $36 \%$ higher than the minimum value informed by the standard, an ultimate tensile strength $2.12 \%$ higher than the minimum value and an increase elongation $11.7 \%{ }^{9}$. Although there was a reduction in martensite content, there was an increase in the content of bainite justifying the reduction in elongation.

The 580-15 sequence presented a yield strength within $20 \%$ higher in relation to the minimum value informed by the manufacturer, an ultimate tensile strength $8.62 \%$ less than the minimum value and an elongation 37.3\% higher ${ }^{9}$. The reduction in strength limit is justified by the reduction in the martensitic content and an increase in the bainitic content, also justifying the gain in elongation.

The 680-15 sequence presented a yield strength $8 \%$ higher in relation to the minimum value informed by the manufacturer, an ultimate tensile strength $12,25 \%$ lower than the minimum value and a deformation $97.3 \%$ higher ${ }^{9}$. The low value of the strength limit is justified by the microconstituents presents: a high content of ferrite and with the pearlite still 


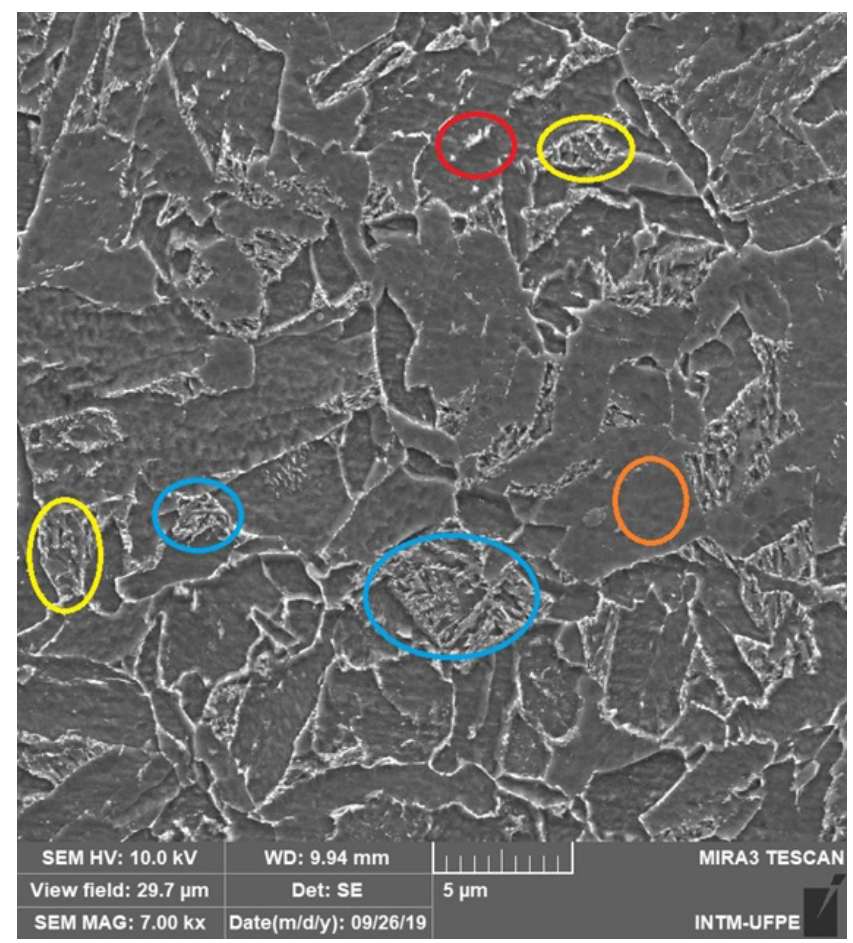

Figure 6. Microstructure of the material produced by the 480-15 sequence.

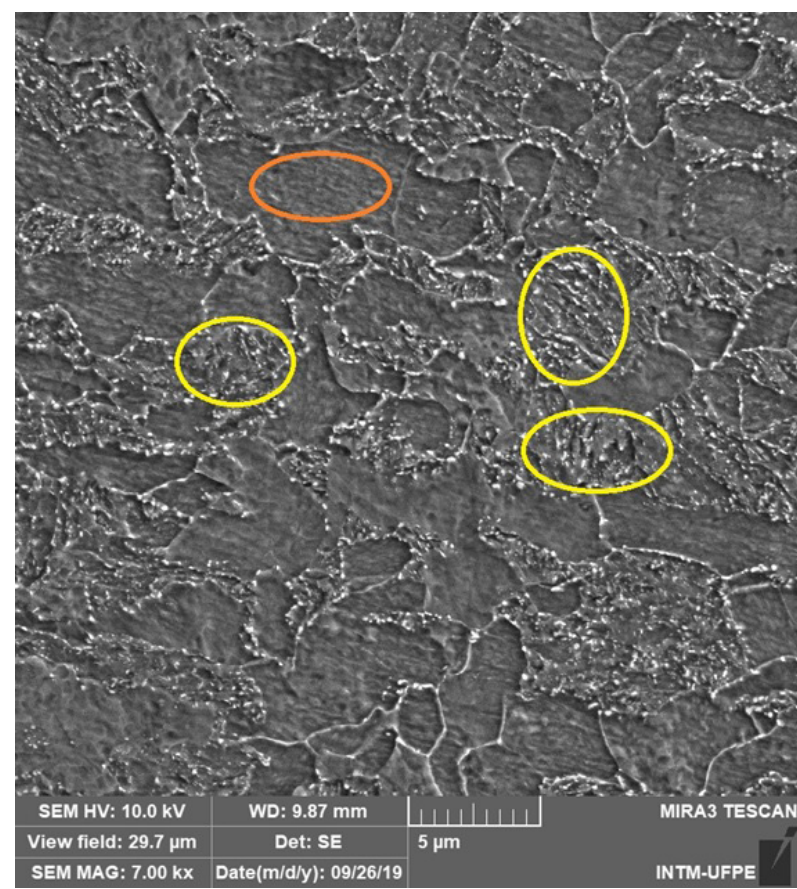

Figure 7. Microstructure of the material produced by the 580-15 sequence.

in formation ${ }^{6}$. The good ductility of the ferrite justifies the increase in elongation.

Using AHSS steel DP800, Nasser et al. ${ }^{2}$ and Silva ${ }^{6}$, also used thermal sequences similar to ours to evaluate its mechanical properties. The results obtained were similar to those obtained in this. Pedrosa et al. ${ }^{10}$ and Castro et al. ${ }^{11}$ to increase the mechanical properties in high-strength and low-alloy steels (HSLA) have already successfully used Thermomechanical sequences, similar to those used in this work.

Working with Transformation-Induced Plasticity (TRIP) Steel $(0.4 \% \mathrm{C} ; 2.0 \% \mathrm{Mn} ; 1.8 \% \mathrm{Si} ; 0.5 \% \mathrm{Cr})$, Gao et al. ${ }^{12}$ applied heat treatment sequences to decompose austenite, generating as a result bainite in a retained austenite matrix. 


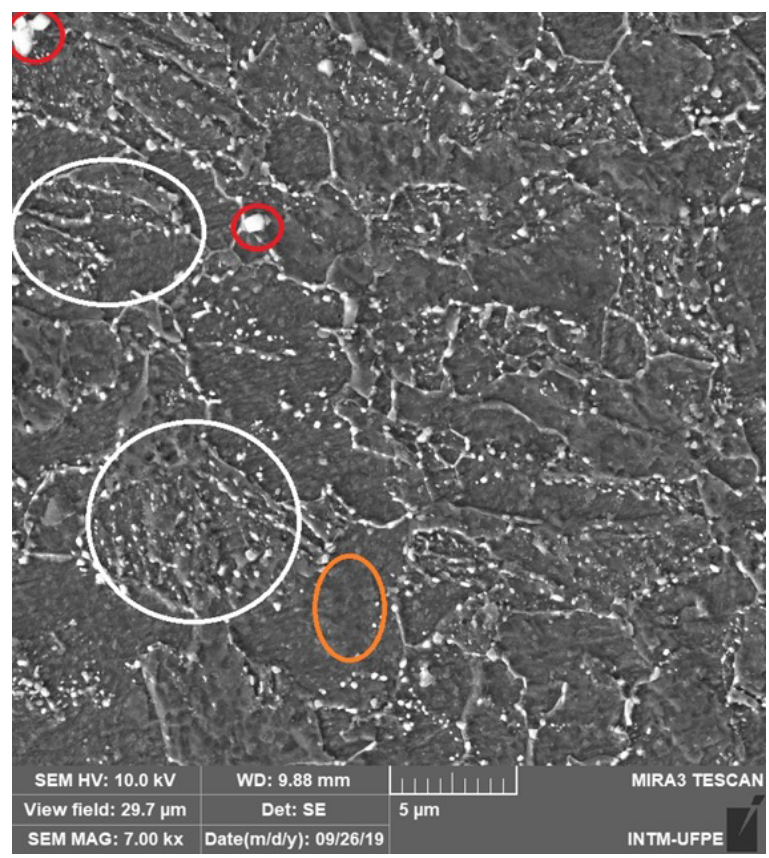

Figure 8. Microstructure of the material produced by the $680-15$ sequence.

From the austenitized material at $880^{\circ} \mathrm{C}$ for 40 minutes, two different samples were produced: the first (FQ) cooled rapidly $\left(50^{\circ} \mathrm{C} / \mathrm{s}\right)$ and the other (SQ) cooled slowly $\left(10^{\circ} \mathrm{C} / \mathrm{s}\right)$ until the temperature $190^{\circ} \mathrm{C}$. Subsequently, partitioning at $360{ }^{\circ} \mathrm{C}$ for a period of 5 to 30 minutes and chilled to room temperature. Finally, all samples were quenched at $280^{\circ} \mathrm{C}$ for two hours.

In these heat treatment conditions, the bainite formed in the retained austenite produces a good combination of strength and ductility, generating a strength limit of $1688 \mathrm{MPa}$ and $25.2 \%$ elongation. Our results show significant differences that are justified by the difference and composition of the steel and by the nature of the applied sequences.

\section{Conclusion}

Different thermomechanical sequences were produced, at four different temperatures, $380^{\circ} \mathrm{C}, 480^{\circ} \mathrm{C}, 580^{\circ} \mathrm{C}$ and $680^{\circ} \mathrm{C}$, in order to modify the microstructures relation to the "as received" condition of DP800 steel.

After each thermomechanical sequence produced, mechanical properties were determined and associated to the phases present in each one of the different microstructures.

The 380-15 sequence presented martensite, ferrite and constituent M-A microstructures. Its thermomechanical treatment increased the ultimate tensile strength (in 14.35\%) and the yield strength (56\%) and reduced the stretching (5.7\%).

The microstructure produced in sequence $380-30$ was martensite, ferrite, constituent M-A and Bainite in a small amount. It presented the same $56 \%$ increase in the yield strength, as the $380-15$ sequence, a gain of $20.62 \%$ in the ultimate tensile strength and $11.4 \%$ in the stretch.

The microstructure produced by the $480-15$ sequence showed a reduction in martensite and an increase in the bainite content. As a result of this, the yield strength increased (around 36\%), and also the ultimate tensile strength $(2.12 \%)$ and the elongation (11.7\%).

Similar mechanical performance was observed for the 580-15 sequence, compared to the previous one. The ultimate tensile strength increased by $8.62 \%$, the yield strength by $20 \%$ and the elongation by $37.3 \%$.

The 680-15 sequence presented a high content of ferrite and with the pearlite still in formation. Because of this, there was an increase of $8 \%$ in the yield strength, $12.25 \%$ in the ultimate tensile strength and $97.3 \%$ in the elongation.

\section{References}

1. Tamarelli CM. The evolving use of advanced high-strength steels for automotive applications [Internet]. Washington: Auto Steel; 2017 [cited 2017 Mar 1]. Available from: http://www. autosteel.org

2. Nasser A, Yadav A, Pathak P, Altan T. Determination of the flow stress of five AHSS sheet materials (DP 600, DP 780, DP780-CR, DP 780-HY and TRIP 780) using the uniaxial tensile and the biaxial Viscous Pressure Bulge (VPB) tests. J Mater Process Technol. 2010;210:429-36. http://dx.doi.org/10.1016/j. jmatprotec.2009.10.003.

3. Zavattieri PD, Savic V, Hector LG, Fekete JR, Tong W, Xuan Y. Spatio-temporal characteristics of the Portevin-Le Châtelier effect in austenitic steel with twinning induced plasticity. Int J Plast. 2009;25:2298-330. http://dx.doi.org/10.1016/j. ijplas.2009.02.008.

4. ASTM International. ASTM E8/E8M-16a: Standard Test Methods for Tension Testing of Metallic Materials: West Conshohocken: ASTM International; 2016.

5. Bhadeshia HKDH, Honeycombe R. Steels: microstructure and properties. Cambridge: Butterworth-Heinemann; 2017.

6. Silva KC. Estudo de sequências termomecânicas em aços AHSS de primeira geração [dissertation]. Recife: Universidade Federal de Pernambuco; 2019. 
7. Senuma T. Physical metallurgy of modern high strength steel sheets. ISIJ Int. 2001;41:520-32. http://dx.doi.org/10.2355/ isijinternational.41.520.

8. Bleck W, Phiou-on K. Effects of microalloying in multi phases steels for car body manufacture. London: Springer; 2009. p. 145-163. https://doi.org/10.1007/978-1-84882-454-6_9.

9. Keeler S, Kimchi M, Mooney PJ, editors. Advanced high-strenght steels application guidelines. China: World Auto Steel; 2017 [cited 2017 Feb 15]. UltraLight Steel Auto Body - Advanced Vehicle Concepts (ULSABAVC). Available from: http://www. worldautosteel.org/download_files/AHSS\%20Guidelines\%20 V6/00_AHSSGuidelines_V6_20170430.pdf
10. Pedrosa IRV, Castro RS, Yadava YP, Ferreira RAS. Study of phase transformations In API 5L X80 Steel in order to increase its fracture toughness. Mater Res. 2013;16:489-96. http://dx.doi. org/10.1590/S1516-14392013005000024.

11. Castro RS, Ferreira RAS, Pedrosa IRV, Yadava YP. Effects of thermomechanical treatment on the occurrence of coincident site lattice boundaries in high strength low alloy steel. Mater Res. 2013;16:1350-4. http://dx.doi.org/10.1590/S1516-14392013005000132.

12. Gao G, Zhang H, Zhunli T, Wenbo L, Bingzhe B. A carbidefree bainite/martensite/austenite triplex steel with enhanced mechanical properties treated by a novel quenching-partitioningtempering process. Mater Sci Eng. 2013;559:165-9. http:// dx.doi.org/10.1016/j.msea.2012.08.064. 